\title{
The Analysis on Causes of Public Skiing Accidents Based on Data Mining
}

\author{
Yang Zhi-lin*1, Fan Jun-qing ${ }^{2, a}$ \\ ${ }^{1}$ Department of Physical Education, Jilin Institute of Chemical Technology, Jilin, Jilin, China \\ ${ }^{2}$ Department of Preschool Education, Normal College of Beihua University, Jilin, Jilin, China \\ *yzlin422@163.com \\ afanjq20070128@126.com
}

\begin{abstract}
Based on data mining, using the 2-4 model of accident causes, 53 cases of skiing accidents are analyzed by mathematical statistics method. According to the research, the direct cause of public skiing accidents is the unsafe actions of the people who caused the accidents. In particular, the unsafe actions of people who fail to keep a safe distance in skiing have the highest frequency, accounting for $37.28 \%$ of the accident rate. The unsafe material state is that the protective net fails to play a protective role, accounting for $31.58 \%$ of the accident rate. The indirect cause is short of safety knowledge and safety awareness for skiers, staffs in the skiing resort and skiing instructors. The primary cause is lack of safety management system for skier family, skier unit and skiing resort. Lack of safety culture in the accident organization is the root cause.
\end{abstract}

Keywords: “2-4”model, skiing, safety

\section{INTRODUCTION}

The North American market remained strong in 2019, while the European market remained stable and the Japanese and Korean markets declined significantly. The Chinese skiing market is the only one growing rapidly in the world. ${ }^{[1]}$ The number of skiers rose to 20.9 million in 2019 from 19.7 million in 2018 which means a year-onyear increase of 6.09 percent. ${ }^{[2]}$ The increase in the number of skiers is a great positive trend for the skiing industry, but it also brings with the increasingly prominent problems of skiing safety. According to the research, the main reasons for the public skiing accidents are skiers' technical restriction, inadequate protection facilities and equipments in skiing resort and backward security system of skiing sports. ${ }^{[3]}$ Some scholars believe that the reasons of skiing injury are mainly related to skiers themselves, management in the skiing resort and skiing equipments. There are also technical factors, external environmental factors, physiological factors and psychological factors for analysis. ${ }^{[4]}$ According to major skiing accidents over the past decade of the National Regional Skiing Association's statistics, injuries have ranged from a skier crashing out of control, an accident on a lift or conveyor belt or snowfield collapse and resulted in paralysis, spinal fractures and head injuries. ${ }^{[5]}$
At present, the research on public skiing accidents mainly includes the investigation of injury site and the analysis of injury causes. The public skiing injuries are caused by the skiers' low level from the dominant factor, but also expose the hidden problems of the safety management of the skiing resort, the safety production of the skiing resort and the safety culture of the skiing resort. Skiing injuries occur frequently. Are there any correlations between injury factors? Can the actual causes of the accident be found through the correlation between the injury factors? Based on the general 2-4 model of accident causes, this paper explores the causes of skiing accidents, clarifies the direct, indirect, fundamental and root causes of skiing accidents and then puts forward targeted strategies to protect 300 million people on ice and snow.

\section{MATERIALS AND METHODS}

In this research,the object of the research is the cause of public skiing accident behavior. With the website of Chinese adjudication documents as the data source, skiing sports as the key words, the limited time is 2019 , 53 real cases were obtained. The 2-4 model of accident causes was used to analyze the behavior causes of skiing accidents. Accident Cause 2-4 Model is a general method 
of accident analysis which can be used in accident cause analysis and accident prevention strategy design.

${ }^{[6]}$ Accident causes can be divided into internal and external causes and internal causes can be divided into organizational behavior and individual behavior. Organizational behavior is divided into guiding behavior and running behavior and individual behavior is divided into habitual behavior, one-time behavior and material state.

\section{THE ANALYSIS ON CAUSES OF PUBLIC SKIING ACCIDENTS}

\subsection{Direct Causes}

\subsubsection{Unsafe actions}

According to the 2-4 model, unsafe actions are those that lead to or have an important relationship with the occurrence of the current accident. ${ }^{[7]}$ The occurrence of unsafe actions is not only the accident initiator, but also includes other personnel in the organization. The unsafe actions of the accident initiator which are closest to the accident in time are the direct cause of the accident. The unsafe actions of other personnel will have an impact on the accident and leave hidden dangers for the occurrence of the accident. This paper analyzes the unsafe movements according to this principle and the statistics of the unsafe movements of 53 accidents are as follows.

Table 1. Analysis of unsafe movements caused by skiers' own reasons in skiing accidents

\begin{tabular}{|c|c|c|c|}
\hline $\begin{array}{c}\text { num } \\
\text { ber }\end{array}$ & contents of unsafe action & $\begin{array}{c}\text { frequenc } \\
\mathrm{y}\end{array}$ & $\begin{array}{c}\text { incidenc } \\
\mathrm{e} \%\end{array}$ \\
\hline 1 & $\begin{array}{c}\text { Not choose the } \\
\text { appropriate sking trail }\end{array}$ & 7 & 11.86 \\
\hline 2 & $\begin{array}{c}\text { Fail to brake and hit the } \\
\text { iron of the protective net }\end{array}$ & 6 & 10.17 \\
\hline 3 & $\begin{array}{c}\text { Stand or walk in the } \\
\text { skiing trail }\end{array}$ & 5 & 8.47 \\
\hline 4 & $\begin{array}{c}\text { Not observe the } \\
\text { surrounding environment }\end{array}$ & 5 & 8.47 \\
\hline 5 & $\begin{array}{c}\text { Not wear helmet, } \\
\text { protective gear } \\
\text { forget to tie shoelaces }\end{array}$ & 4 & 6.78 \\
\hline 6 & $\begin{array}{c}\text { Fail to lookout timely } \\
\text { Not slow down and } \\
\text { dodge effectively }\end{array}$ & 3 & 5.1 \\
\hline 7 & $\begin{array}{c}\text { Minors lack of sking } \\
\text { experience }\end{array}$ & 2 & 3.38 \\
\hline 8 & $\begin{array}{c}\text { Stuck on a motorcycle } \\
\text { trail }\end{array}$ & 1 & 1.69 \\
\hline 9 & $\begin{array}{c}\text { Stay at random } \\
\text { Frolic when skiing }\end{array}$ & 1 & 1.69 \\
\hline 10 & \begin{tabular}{c}
1.69 \\
\hline
\end{tabular} & 1 & \\
\hline
\end{tabular}

Table 2. Analysis of unsafe movements of skiers in skiing accidents that cause injuries to others

\begin{tabular}{|c|c|c|c|}
\hline $\begin{array}{c}\text { numb } \\
\text { er }\end{array}$ & $\begin{array}{l}\text { contents of unsafe } \\
\text { action }\end{array}$ & $\begin{array}{c}\text { frequenc } \\
y\end{array}$ & $\begin{array}{l}\text { incidenc } \\
\mathrm{e} \%\end{array}$ \\
\hline 1 & \begin{tabular}{|c|}
$\begin{array}{c}\text { Fail to control the speed } \\
\text { of the skiing } \\
\text { fail to maintain a safe } \\
\text { distance }\end{array}$ \\
\end{tabular} & 22 & 37.28 \\
\hline 2 & $\begin{array}{l}\text { not know the rules of } \\
\text { skiing } \\
\text { Skiing isn't supervised } \\
\text { by experienced skiers }\end{array}$ & 1 & 1.69 \\
\hline 3 & $\begin{array}{l}\text { not comply with the } \\
\text { skiing standard }\end{array}$ & 1 & 1.69 \\
\hline
\end{tabular}

Table 3. Analysis of unsafe movements of the management personnel in ski resort in skiing accidents

\begin{tabular}{|c|c|c|c|}
\hline $\begin{array}{c}\text { numb } \\
\text { er }\end{array}$ & $\begin{array}{c}\text { contents of unsafe } \\
\text { action }\end{array}$ & $\begin{array}{c}\text { frequenc } \\
\mathrm{y}\end{array}$ & $\begin{array}{c}\text { incidenc } \\
\mathrm{e} \%\end{array}$ \\
\hline 1 & $\begin{array}{c}\text { Fail to fulfill security } \\
\text { obligations }\end{array}$ & 21 & 58.33 \\
\hline 2 & $\begin{array}{c}\text { No enclosure and } \\
\text { warning signs }\end{array}$ & 7 & 19.44 \\
\hline 3 & $\begin{array}{c}\text { Ignore management } \\
\text { and dredge of trail } \\
\text { distance }\end{array}$ & 3 & 8.33 \\
\hline 5 & $\begin{array}{c}\text { No active rescue } \\
\text { unprotected skiers from } \\
\text { entering intermediate or } \\
\text { advanced trail }\end{array}$ & 2 & 5.56 \\
\hline 6 & $\begin{array}{c}\text { Minors are allowed to } \\
\text { ski without being } \\
\text { accompanied by their } \\
\text { guardians }\end{array}$ & 1 & 2.78 \\
\hline
\end{tabular}

Table 4. Analysis of unsafe movements of snowfield coaches in skiing accidents

\begin{tabular}{|c|c|c|c|}
\hline number & contents of unsafe action & frequency & $\begin{array}{c}\text { incidence } \\
\%\end{array}$ \\
\hline 1 & $\begin{array}{c}\text { Coach did not obtain } \\
\text { national qualification }\end{array}$ & 2 & 50 \\
\hline 2 & $\begin{array}{c}\text { Coach relax the safety } \\
\text { escort when shooting a } \\
\text { video }\end{array}$ & 2 & 50 \\
\hline
\end{tabular}

In total, skiers injured others in 24 unsafe manoeuvres, mostly due to collisions. Among them, the accident frequency of not taking necessary deceleration measures to control the gliding speed and not keeping a reasonable safe distance with the front glider is 22 times, with an incidence rate of $37.28 \%$. It is enough to illustrate the high risk of skiing. There are experiments to prove what happens when skiing is blocked on intermediate trails. The experimental results showed that the skis in front of the body scooped it up as soon as the dummy was touched and then the unfocused prover crashed into the mountain carrying the dummy nearly 20 meters down the hill. ${ }^{[8]}$ So 
the only way to avoid risk is to keep a safe distance from other people while skiing.

\subsubsection{Unsafe state analysis}

Unsafe state is the state that leads to the occurrence of the accident or has an important influence on the occurrence of the accident. It is generated by the unsafe action or activated by the habitual behavior. ${ }^{[9]}$ Accidents are not only caused by human beings, but also caused by objects. The unsafe material states in the 2-4 model are divided into whether there is violation of regulations, whether accidents have been caused and whether there is high risk. The identification to unsafe material states is based on rules and accident cases. The unsafe state in this paper is identified according to Chinese Skiing Site Management Standards (2017 Revised Edition) and skiing accident cases according to the 2-4 model.

Table 5. Analysis of unsafe state in skiing accidents

\begin{tabular}{|c|c|c|c|}
\hline number. & contents of unsafe state & frequency & \begin{tabular}{|c|} 
incidenc \\
e \% \\
\end{tabular} \\
\hline 1 & $\begin{array}{l}\text { The protective net fails to } \\
\text { protect and block. } \\
\text { The snow walls below the } \\
\text { safety net less than } 1.5 \\
\text { meters. }\end{array}$ & 6 & 31.58 \\
\hline 2 & $\begin{array}{l}\text { There are snow pits, } \\
\text { bumps and sundries on } \\
\text { the trail. }\end{array}$ & 3 & 15.79 \\
\hline 3 & $\begin{array}{l}\text { Ice broke out under the } \\
\text { skis. }\end{array}$ & 2 & 10.53 \\
\hline 4 & $\begin{array}{l}\text { Failure to distinguish } \\
\text { diffrent trails. No } \\
\text { necessary warning signs. }\end{array}$ & 2 & 10.53 \\
\hline 5 & $\begin{array}{l}\text { The fence design was } \\
\text { flawed. }\end{array}$ & 1 & 5.26 \\
\hline 6 & Skis loose. & 1 & 5.26 \\
\hline 7 & $\begin{array}{c}\text { No physical separation } \\
\text { between adult and child } \\
\text { areas at the bottom of the } \\
\text { trail. }\end{array}$ & 1 & 5.26 \\
\hline 8 & $\begin{array}{l}\text { No safety barriers and no } \\
\text { lighting at the entrance to } \\
\text { the trail }\end{array}$ & 1 & 5.26 \\
\hline 9 & $\begin{array}{c}\text { The column is not } \\
\text { wrapped in elastic soft } \\
\text { material. }\end{array}$ & 1 & 5.26 \\
\hline 10 & $\begin{array}{l}\text { There is no lighting in the } \\
\text { speed reduction area. }\end{array}$ & 1 & 5.26 \\
\hline
\end{tabular}

Statistics show that the accident frequency of the protective net in the unsafe state is the highest. In particular, the accident frequency is 6 times and the incidence rate is $31.58 \%$. The investigation 10 years ago indicated that the protection defect is the main factor causing injury and the injury rate is $16.1 \% \cdot{ }^{[10]}$ The protective net is still the main material state of accidents which indicates that the safety protection and standards of skiling resorts in China are still short boards. Whether the design of the anti-skid net meet the requirements?
How much should the anti-skid net bear? Which material does protective net apply? Relevant national standards still need to be further refined and issued which also shows that there are loopholes in the inspection and supervision to the skiing resort. Survey research shows that ice accident frequency is 5 and the rate is $26.32 \%$ due to ground pit or uneven ground. Although the Chinese Skiing Resort Management Specifications (2017 Revised Edition) stipulates that the thickness of the snow layer after compaction should be no less than $30 \mathrm{~cm}$, there shall be no exposed earth, rocks and other sundry things on the snow surface and no ice shall be formed on the surface of the snow layer. ${ }^{[11]}$ Meanwhile the skiing resort artificial nursing is not sound, so the safety of skiing buried hidden dangers. ${ }^{[12]}$ So skiers should understand the information of the skiing resort as much as possible, such as snow conditions, weather and temperaturethe of day. At the same time, the skiing resort should publish snow information so that skiers can know the information in a timely manner.

\subsection{Indirect Causes}

The reasons that cause people's unsafe actions and the form unsafe state are called indirect reasons which are also the habitual behaviors of the members in the organization. They mainly include five aspects: safety knowledge, safety awareness, safety habits, safety physiology and safety psychology. The skiers lack of safety consciousness, safety knowledge and safety habits, such as walking on the trail, not wearing a helmet and failing to observe surroundings. In fact, skiers should realise that skiing is a high risk sport, should fulfill normal care and attention. However, skiers in the accident did not have alertness to a higher risk for skiing. In addition, skiers used to ignore the skiing rules. Someone cannot effectively slow down and keep a safe distance with people in front mostly because skiers feel that they have no problem in skiing so as to relax their vigilance which is fundamentally caused by the lack of safety knowledge of skiers. Some studies have pointed out that safety knowledge and skills can effectively prevent the occurrence of sports injuries and even accidents. ${ }^{[13]}$ In addition to, the lack of safety awareness and safety knowledge of the administrative staff of the skiing resort is one of indirect causes.

\subsection{Essential reasons}

Lack of safety management system is the essential cause of skiing accidents and safety management system includes safety policy, safety management organization structure and system files such as program files and operation instructions. In the identification process, we should particularly pay attention to the establishment and implementation of program files. ${ }^{[14]}$ On the other hand, there is a lack of safety management and administrative staff not to implement the procedures efficently.The 
reason is that there is no safety management system in some skiing resorts which makes the administrative staff in the skiing resorts unable to find safety risks and record timely. Therefore, the skiing resorts should establish a sound safety management system, formulate safety management plans, carry out safety inspection and compile safety reports.

\subsection{Root causes}

The root cause of the accident is the lack of safety culture of skiing and the problem of safety management system is caused by the members of the organizationthe lack of understanding of safety culture. Compared with the 32 elements of safety culture in the 2-4 model of accident causes, ${ }^{[15]}$ this paper explores the problem of lacking safety culture of organization members in skiing accidents. For example, administrative staff in the skiing resort failed to integrate safety into the management system, safety importance, safety training requirements and safety system implementation resulting in the failure to fully fulfill the safety obligations and rescue actively. Public skiers have no consensus on skiing safety management, lack of emergency response ability and lack of safety awareness which lead to the occurrence of behaviors.

\section{CONCLUSIONS}

With the increasing number of skiing resorts in China, improving the safety management of skiing resorts is a realistic requirement for the development of skiing resorts. Based on the theory of accident cause, the causes of skiing accidents are analyzed including unsafe action, unsafe state, habitual behavior, safety management and safety culture.

From the analysis of one-time behavior and habitual behavior, it can be concluded that the most unsafe behaviors leading to the public skiing accidents include no taking necessary deceleration measures to control the skiing speed and no keeping a reasonable safe distance from the skater in front. The most frequent occurrence of unsafe material states is that the protective net fails to play an effective role in protection and blocking.

From the analysis on the causes of operation behavior, there are some deficiencies in the management program of the skiing resort and the lack of implementation which leads to the deficiency of the safety management system of the skiing resort. Administrative staff in the skiing resort failed to understand the safety concept deeply leading to the lack of skiing safety culture.

\section{ACKNOWLEDGMENT}

This work is the subject of the 13th five-year Social Science Research Project of Jilin Provincial Department of Education (JJKH20200259SK).

\section{REFERENCES}

[1] Sohu Network. (2019) 2019 global skiing market reportstarting at the same time around the world. https://www.sohu.com/a/333582656_120138263.

[2] Sohu Net. (2019) White Paper on China's skiing industry (annualreport in 2019). https://www.sohu.com/a/376520666_503564.

[3] Wei, Y N, Wu, C X. (2017) Research on the Accident Causing and Preventive Measures of Public Skiing Sports in China. Guizhou Sports Science and Technology, 3:37-39.

[4] Liu, J, Ju, L. (2012) Injury Factors and Preventive Measures of Skiing Sports Injury. Snow and Ice Sports, 34:34-37.

[5] Chen, Z F, Jing, T. (2019) Research on accident injury and safety protection of skiing in winter. Snow and Ice Sports, 41:33-37.

[6] FU, G. (2013) Safety Management - Behavior Control Method for Accident Prevention. Science Press, Beijing.

[7] Gao, J Y, Jia Q S, Fu, G. (2017) Research on Behavioral Causes of Barrier Wounding Accidents. Industrial Safety and Environmental Protection,43:54-57.

[8] the CCTV Network. (2017) Analysis of Skiing Mistakes. HTTP: http://tv.cctv.com/2017/01/10/ARTIgaIYotFBheSG 8TpEgeca170110.

[9] Fu, G, Wang, X M, Li, Ya. (2017) Journal of Safety and Environment, 17:1003-1008.

[10] Zhang, G H, Huang, Q. (2008) Research on Safety Problems of Ski Resort. Snow and Ice Sports, 1:8386.

[11] General Administration of Sport of China. (2017) China's ski areas management specification (revised in 2017). http://www.sport.gov.cn/dyzx/n5169/c832021/cont ent.html.

[12] Yao, J S. (2011) Research on the Safety of Public Ski Tourism in China. Heilongjiang University, 36-67.

[13] Ding, L, Gao, X W, Zhang, L. (2019) The influence of skiing skills on high risk sexual behavior in public skiing: A moderated moderating effect model. Snow and Ice Sports, 41:30-36.

[14] Fu, G. (2019) Behavioral safety from the perspective of "2-4" model. Modern Occupational Safety, 12:1719. 